\title{
The development of a novel urea sensor using polypyrrole
}

\author{
Anita Hamilton ${ }^{*, 1,2}$, Carmel B. Breslin ${ }^{1,2}$ \\ Department of Chemistry, National University of Ireland Maynooth, Maynooth, Co. Kildare, Ireland
}

\section{A R T I C L E I N F O}

\section{Article history:}

Received 21 April 2014

Received in revised form 6 August 2014

Accepted 7 August 2014

Available online 6 September 2014

\section{Keywords:}

Polypyrrole

Urea sensor

Urease

Cyclodextrin

Ascorbic acid

\begin{abstract}
A B S T R A C T
The urease enzyme (Urs) was successfully incorporated into a polypyrrole film (PPy) in one simple electropolymerisation step. The films were formed using different dopant anions. The polypyrrole-urease-chloride film (PPy-Urs-Cl) was deposited from a simple chloride dopant, and the polypyrrole-urease-sulfonated- $\beta$-cyclodextrin (PPy-Urs-SCD) was formed using a sulfonated- $\beta$ cyclodextrin (SCD) dopant. The presence of the Urs within the polymer film was evident from the fibrous morphology, observed in the SEM micrographs, and the presence of nickel, arising from the active site of the urease enzyme. The sensing ability of the films and their enzyme-free counterparts (i.e., $\mathrm{PPy}-\mathrm{Cl}$ and PPy-SCD) towards urea was investigated. The dopant anion plays an important role in the sensitivity of the polymer films towards urea. The PPy-Urs-SCD film has a superior sensitivity of $5.79 \mu \mathrm{C} \mu \mathrm{M}^{-1} \mathrm{com}^{-}$ pared to $0.76 \mu \mathrm{C} \mu \mathrm{M}^{-1}$ for the PPy-Urs-Cl polymer film. Furthermore, the negative groups on the SCD eliminate interference from common interfering compounds, such as ascorbic acid.
\end{abstract}

(c) 2014 Elsevier Ltd. All rights reserved.

\section{Introduction}

Urea is an important molecule in both the agricultural and medical industries and it is often monitored in the blood as it can act as an indicator of renal disease in the human body. Excess nitrogen in the form of urea is dissolved in the blood and then excreted by the kidneys as a component of urine. In addition, a small amount of urea is also excreted via sweat/perspiration, along with salts and water. If this excess nitrogen is not excreted, ammonia can build up in the body to high levels which leads to cell toxicity and eventually to death [1]. The normal blood levels of urea range from 2.5 to $7.5 \mathrm{mM}$, depending on the build and relative health of the body [1]. Above $7.5 \mathrm{mM}$, the patient is said to be suffering from renal deficiency, and the kidneys fail to excrete the excess nitrogen successfully. Hence, it is very important to monitor the level of urea to determine the health of the kidneys in the human body [2,3].

The simplest method of monitoring the urea concentration is to immobilise the urease enzyme (Urs) onto an electrode. This has been widely investigated throughout the literature and proves to be the most promising approach [2]. The urease enzyme can be immobilised onto an electrode by covalent binding to a

\footnotetext{
* Corresponding author. Tel.: +353 85 1556525; fax: +353 17083815 . E-mail addresses: anita.hamilton@nuim.ie (A. Hamilton), carmel.breslin@nuim.ie (C.B. Breslin).

1 ISE member.

2 ECS member.
}

conducting polymer film, or by entrapment during the electrodeposition of the polymer film onto the electrode. A wide range of conducting polymers has been used for the entrapment of urease, including polypyrrole (PPy), polyaniline (PAni) and polythiophene, and their derivatives [4].

The immobilised urease electrode was first proposed in the 1970s by Guilbault and Montalvo [5], who monitored the formation of ammonium ions from urea, catalysed by the urease enzyme as described in Equation 1.

$\mathrm{NH}_{2} \mathrm{CONH}_{2}+3 \mathrm{H}_{2} \mathrm{O} \stackrel{\text { Urease }}{\longrightarrow} 2 \mathrm{NH}_{4}^{+}+\mathrm{HCO}_{3}^{-}+\mathrm{OH}^{-}$

Since then, the entrapment of urease within a polymer matrix has gained a lot of attention, with polypyrrole and polyaniline being the most common choice of conducting polymers [6-10]. An electroactive polyaniline film has been used for urea detection whereby the urease enzyme was entrapped within the electroactive polymer during electrodeposition $[9,10]$. An electroactive polypyrrole with a polyion complex has been utilised as a composite film for the detection of urea, where the polyanion included PAA (polyacrylate) and PSS (polystyrene sulfonate) with PLL (polylysine) as the polycation. The urease enzyme was entrapped within the polyion composite film and a stable, rapid response signal for urea was achieved $[7,8]$. Additionally, Adeloju et al. [11,12] have developed a polypyrroleurease (PPy-Urs) film that detects urea using flow injection analysis, a concept that was also utilised by Walcerz and co-workers with promising results [13]. In more recent years, urea has been detected by ion selective optical sensors that detect the ammonium ions generated from urea via the urease enzyme [14] and by ion selective 
field effect transistors (ISFETs) [15-17]. Co-polymers have also been employed. Rajesh et al. [18-20] synthesised a polypyrrole based co-polymer for the amperometric detection of urea with a short response time and good electrode stability.

This paper is focused on the development of a novel urea sensor formed by the entrapment of the urease enzyme within a polypyrrole matrix. This has been carried out previously [1,21], however, poor detection limits were obtained. To further enhance the detection of urea in solution, while repelling common interferants, such as uric acid and ascorbic acid, an anionic cyclodextrin was incorporated into the polypyrrole matrix together with the urease enzyme.

\section{Experimental}

\subsection{Chemicals}

The chemicals used throughout this study were purchased from Sigma-Aldrich or its subsidiary company Fluka. The urease enzyme chosen was the Jack Bean Urease from the Canavalia ensiformis plant as it contains two nickel atoms in its active site [2], which would be easy to detect using techniques such as SEM and EDX. The urease enzyme was dissolved in the electropolymerisation solution to give a concentration of $4000 \mathrm{mg} \mathrm{dm}^{-3}$. All chemicals were used as supplied expect for pyrrole which was vacuum-distilled and stored in the dark at $-20^{\circ} \mathrm{C}$ prior to use. All other solutions were made from a stock solution of $\mathrm{pH} 7.0,0.05 \mathrm{M}$ phosphate buffer, which was initially prepared using distilled water. This concentration of phosphate buffer was chosen as higher concentrations are known to interfere with the biocatalytic activity of urease, whereas lower concentrations have insufficient conductivity [9]. All of the solutions were freshly prepared before each experiment.

\subsection{Instrumentation}

Potentiostatic and cyclic voltammetry experiments were carried out using a Solartron Potentiostat Model 1287. All measurements were performed at room temperature (approximately $25^{\circ} \mathrm{C}$ ) in a standard three-electrode cell with a platinum $(\mathrm{Pt})$ working electrode, a high surface area platinum wire counter electrode and a SCE reference electrode. The Pt electrodes ( $4 \mathrm{~mm}$ in diameter) were encased in a larger Teflon ${ }^{\circledR}$ sheath and set in place using a nonconducting epoxy resin. The electrical contact was made with a copper wire attached using a highly conducting silver-loaded resin. The working electrodes were polished to a smooth surface, mirror finish, using 30,15, 6 and $1 \mu \mathrm{m}$ diamond suspensions on microcloth (Buehler), sonicated in distilled water and then in ethanol to remove any polishing residues, and finally rinsed with distilled water and dried.

\subsection{Fabrication of the Urs immobilised into polypyrrole (PPy) films}

The Urs was immobilised into the polypyrrole (PPy) films in a single-step by physical entrapment of the enzyme into the conducting polymer during electrodeposition. The films were electrochemically prepared onto the platinum working electrode at a fixed potential of $0.70 \mathrm{~V}$ vs. SCE from an aqueous solution containing pyrrole monomer $(0.50 \mathrm{M})$, Urs $\left(4000 \mathrm{mg} \mathrm{L}^{-1}\right)$ and $\mathrm{NaCl}$ $(0.10 \mathrm{M})$ for the PPy-Urs-Cl films and from a solution containing pyrrole monomer $(0.50 \mathrm{M})$, Urs $\left(4000 \mathrm{mg} \mathrm{L}^{-1}\right)$ and sulfonated- $\beta$ cyclodextrin $(0.02 \mathrm{M})$ for the PPy-Urs-SCD films. The PPy-Cl and PPy-SCD films were prepared in the absence of the urease enzyme for comparative purposes. Although it would be expected that the activity of the Urs would decrease upon its immersion in the conducting electrolyte [22], no significant decrease of the enzyme activity was observed. The polymer films were deposited until a fixed charge of $0.10 \mathrm{C} \mathrm{cm}^{-2}$ was achieved. The thickness of the films obtained was approximated as $3.55 \mu \mathrm{m}$, which was theoretically calculated using the charge thickness ratio derived by Diaz et al. [23] for a simple chloride dopant. In this analysis it is assumed that $1.0 \mathrm{C} \mathrm{cm}^{-2}$ of charge passed is equivalent to $2.5 \mu \mathrm{m}$ of polymer film. It is important to mention that the theoretical values of thickness obtained for the PPy-Urs-Cl, PPy-SCD and PPy-Urs-SCD films are only an approximation, as the films doped with the large anionic groups may not have the same charge to polymer thickness ratio as the PPy-Cl films [24,25]. All of these films were characterised using SEM and EDX analysis and then investigated as suitable sensors for the detection of urea.

\section{Results and Discussion}

\subsection{Formation of PPy-Urs using a potentiostatic mode}

The urease enzyme was incorporated into the polymer film by physical entrapment during the deposition of the polymer at a fixed potential of $0.70 \mathrm{~V}$ vs. SCE. The PPy-Urs-Cl film was deposited from a $0.10 \mathrm{M} \mathrm{NaCl}$ solution containing $4000 \mathrm{mg} \mathrm{L}^{-1} \mathrm{Urs}$ and $0.50 \mathrm{M} \mathrm{pyr}-$ role, while the enzyme-free, $\mathrm{PPy}-\mathrm{Cl}$, was deposited from a pyrrole solution containing $0.10 \mathrm{M} \mathrm{NaCl}$. The sulfonated- $\beta$-cyclodextrin (SCD), which is a polyanion as shown in Fig. 1, has a high conductivity and a $0.02 \mathrm{M}$ SCD solution with $4000 \mathrm{mg} \mathrm{L}^{-1} \mathrm{Urs}$ and pyrrole was used to deposit the PPy-Urs-SCD film at $0.70 \mathrm{~V}$ vs. SCE. The corresponding film in the absence of urease was also formed.

The current-time plots recorded during the formation of the PPy-Urs-Cl, PPy-Cl, PPy-Urs-SCD and PPy-SCD films are shown in Fig. 2. It is clear that the current-time plots for the chloridecontaining films differ significantly from the data recorded for the SCD-containing films. Initially, there is a rapid decrease in the current, which arises from the charging of the double layer. This is (a)

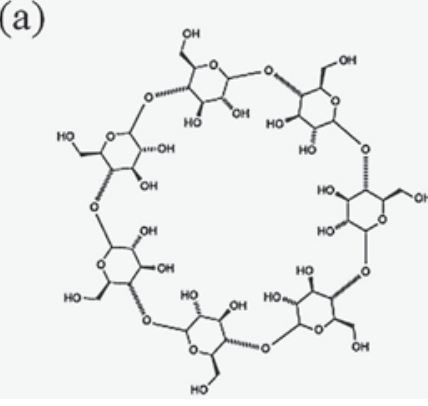

(b)

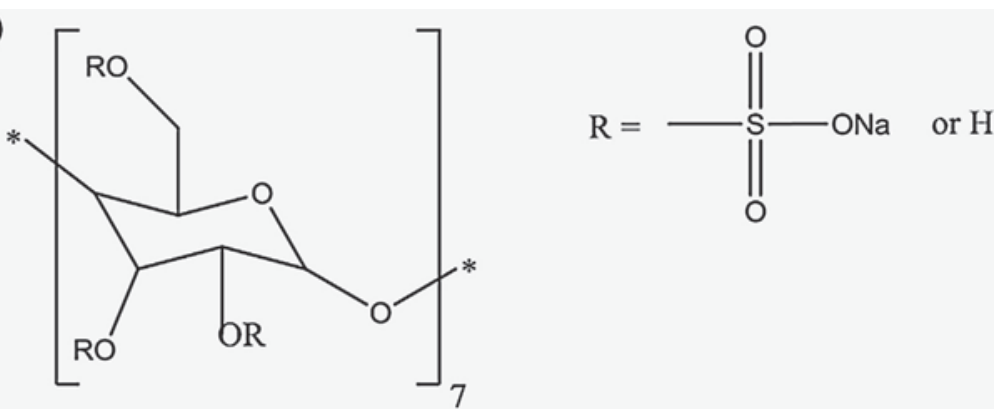

Fig. 1. (a) The structure of beta cyclodextrin in the absence of sulfonated molecules and (b) the formula and structure of sulfonated beta cyclodextrin (SCD). 


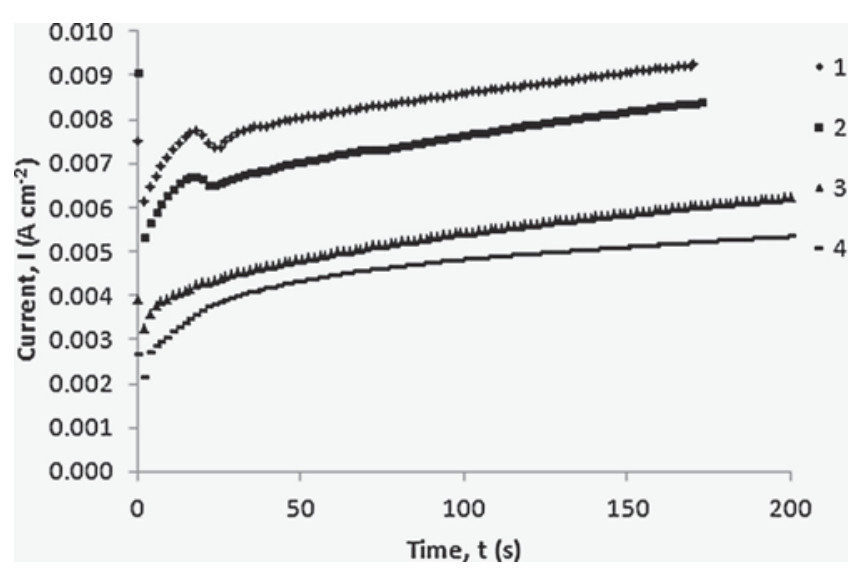

Fig. 2. Current plotted as a function of time for the formation of 1 PPy-SCD, PPy-Urs-SCD, $\triangle 3$ PPy-Cl and -4 PPy-Urs-Cl on a Pt electrode at 0.70 V vs. SCE.

then followed by a fast rise in the current, which corresponds to the nucleation and growth of the polymer film [26]. Then for the chloride-containing films, Fig. 2, curves (3) and (4), there is a further more gradual increase in the current as the polymer is deposited onto the working electrode to give a higher surface area. However, with the SCD-containing films, this rapid increase in current reaches a maximum value within a number of seconds, typically 20 $\mathrm{s}$, which is characteristic of the SCD electrolyte [27], at which time the current begins to decrease again. This is then followed by a further more gradual increase in the current as the polymer becomes deposited onto the working electrode $[24,28]$.

One possible explanation for these current-time transients may be the polyelectrolyte properties of the SCD [24]. As no other supporting electrolyte was used, these polyanions will migrate to the positively charged platinum surface on application of the potential. This gives rise to a high local concentration of the SCD anions during the initial stages of electropolymerisation. Once the monomer oxidation is initiated, the electropolymerisation reaction proceeds at a very high rate in the presence of the high concentration of SCD. However, as the electropolymerisation reaction proceeds, the concentration of the SCD anions is reduced as they are doped within the polypyrrole layers deposited onto the electrode, and the rate of the electropolymerisation reaction is now dominated by the transport and diffusion of the large SCD anions to the interface. The diffusion of the SCD anions is slow due to the size of the SCD with 7-11 sulfonate groups and this gives rise to a drop in the rate of electropolymerisation which is consistent with the slight dip in the current at approximately 20 s, Fig. 2.

It is also evident from Fig. 2 that the addition of Urs decreases the rate of polymer growth for both the chloride-containing film (curve 4) and the SCD-containing film (curve 2). This is due to Urs being a large enzyme that inhibits access of the monomer to the electrode surface, resulting in slower nucleation and hence, polymer growth [29].

\subsection{Characterisation of the polymer films using SEM and EDX}

The surface morphologies of the PPy-Cl, PPy-Urs-Cl, PPy-SCD and PPy-Urs-SCD polymer films were characterised using scanning electron microscopy. A typical SEM micrograph of $\mathrm{PPy}-\mathrm{Cl}$ is shown in Fig. 3a, with the characteristic cauliflower morphology of polypyrrole evident [30]. In contrast, Fig. 3b shows an SEM micrograph of the PPy-Urs-Cl polymer film, which exhibits a large number of fibres. Similarly, in Fig. 3c, evidence of the characteristic cauliflower morphology of PPy is observed for the PPy-SCD polymer film, whereas the urease enzyme incorporated into the polymer film creates a fibrous morphology, as shown in Fig. 3d.
The urease containing polymer film has a fibrous morphology due to the incorporated enzyme, whereas the films without urease are very different and do not show any evidence of this fibrous morphology. In addition, the PPy-Cl and PPy-SCD films have the typical cauliflower morphology of polypyrrole owing to the nuclei forming quickly in the presence of the doping anions and the bulk polymer subsequently growing preferentially around the nucleation sites [30]. It is clearly evident from the SEM micrographs that the PPyUrs-SCD film is porous. This may be related to the size of the SCD and the urease enzyme which are both large species. As these large species are incorporated within the polypyrrole matrix a porous film is generated.

EDX measurements were also carried out on the PPy-Cl, PPyUrs-Cl, PPy-SCD and PPy-Urs-SCD polymer films, and the EDX spectra are shown in Figs 4a, b, c and d, respectively. The EDX spectra of the two chloride-containing polymer films clearly show the presence of chloride in both polymer films due to the incorporation of chloride as a dopant anion, whereas, in the SCD-containing films, sulfur is observed, arising from the sulfonated groups on the sulfonated- $\beta$-cyclodextrin. The dopant anion is incorporated during the electropolymerisation of pyrrole at $0.70 \mathrm{~V}$ vs. SCE, to generate the oxidised PPy which has a positive charge. The dopant anion is important in the growth of polypyrrole films as different sized ions lead to different dopant levels within the polypyrrole film [31,32]. The significant difference between the EDX spectra in the presence and absence of urease is the presence of the nickel in the urease-containing films, which is absent in the other films. This nickel is contained in the active site of the Jack Bean urease enzyme [2], and its presence in the EDX spectra of the PPy-Urs-Cl and PPy-Urs-SCD films is clear evidence and proof that the urease is indeed incorporated successfully into both polymer films.

\subsection{Sensing studies of the polymer films}

Once it was evident that the urease enzyme had been successfully incorporated into both the PPy-Urs-Cl and PPy-Urs-SCD polymer films, the next step was to investigate the sensing abilities of these films towards urea. After polymerisation, the modified electrode was rinsed using distilled water to remove any monomer or enzyme adhering to the surface, then cycled between -0.60 and $0.80 \mathrm{~V}$ vs. SCE in the $0.05 \mathrm{M}$ phosphate buffer at a $\mathrm{pH}$ of 7.0 until a steady state was reached. The electrode was removed and placed into a low concentration of urea in the phosphate buffer. Again, the film was cycled for a fixed number of cycles (usually 10 cycles) and then placed into the next phosphate buffer solution with a slightly higher concentration of urea. This was repeated over a large concentration range, with rinsing of the modified electrode carried out between each solution in order to avoid transfer and contamination of the solutions. Similar experiments were carried out with each of the films.

Although most sensors are amperometric [22], where the current at a fixed potential is monitored, or potentiometric [2], where the potential is recorded, a different approach was taken in this study. On examining the cyclic voltammograms of the modified electrode in the absence and presence of urea (Fig. 5), it is evident that there is an increase in the current in the presence of urea but this extends over the entire electrochemical window, with no welldefined peak in the current. Accordingly, the entire potential range $(-0.60$ to $0.80 \mathrm{~V}$ vs. SCE) was used and the oxidation charge over this potential was computed, producing a coulombometric sensor. As the presence of urea significantly increases the oxidation charge, Fig. 5, the charge arising in the absence of urea, from the background phosphate buffer, can be easily subtracted. Hence, all the results presented are given with the background charge subtracted, and thus represent the true charge arising from the urea. 
(a)

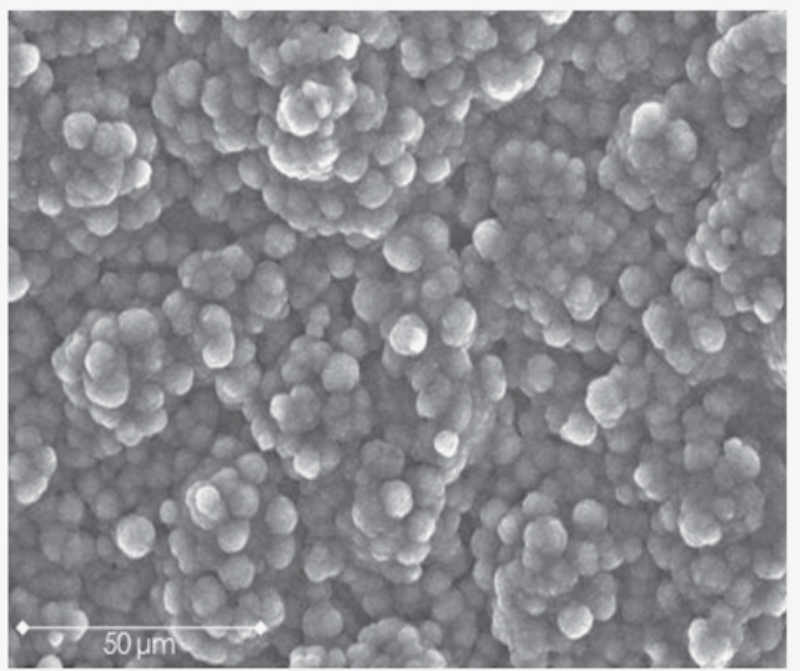

(c)

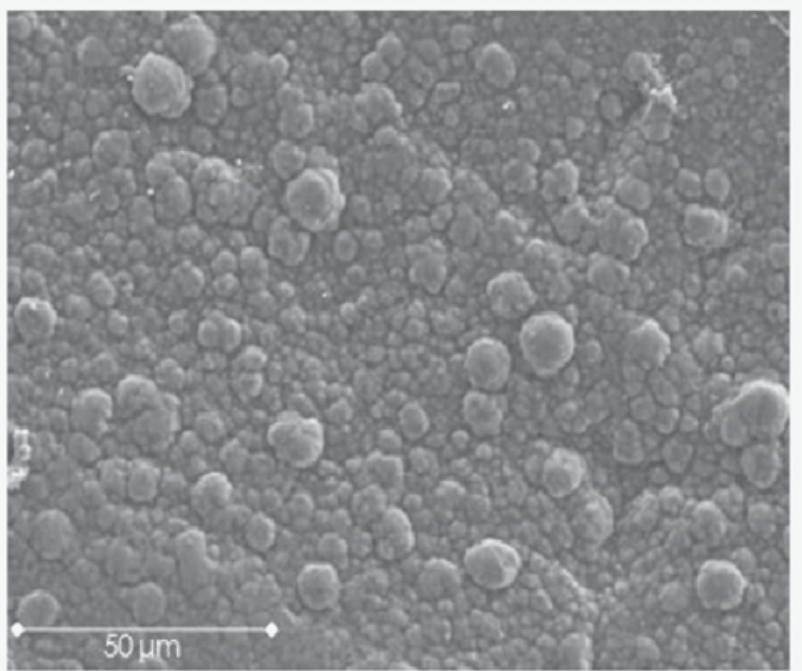

(b)

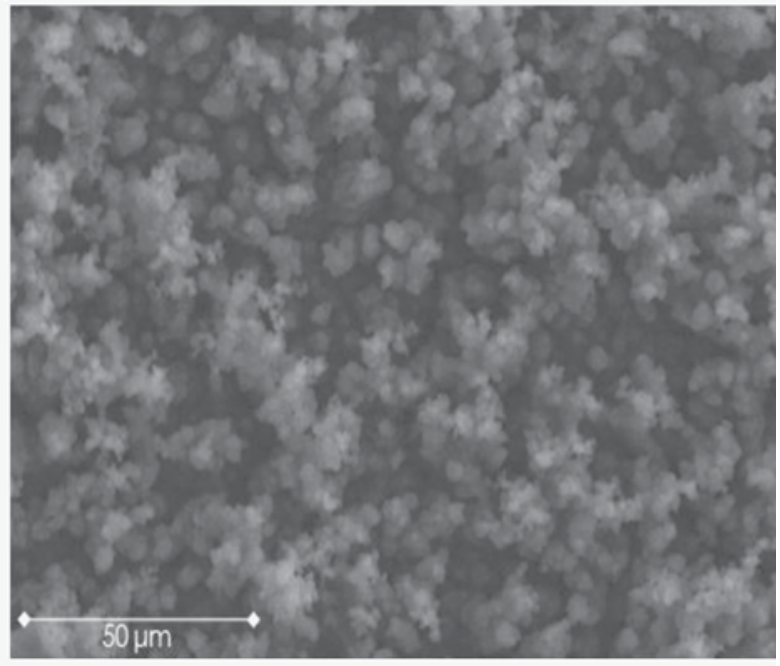

(d)

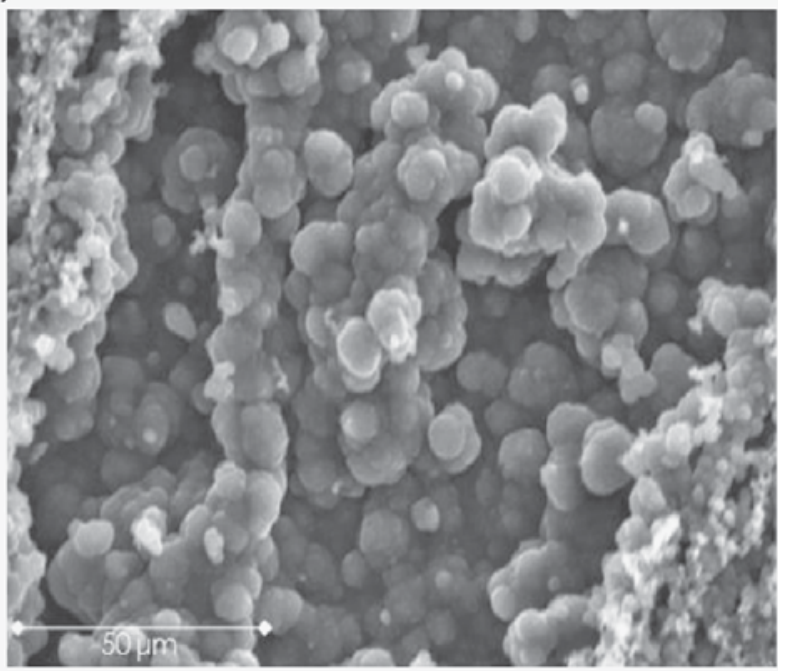

Fig. 3. Scanning electron micrograph of (a) PPy-Cl, (b) PPy-Urs-Cl, (c) PPy-SCD and (d) PPy-Urs-SCD electrodeposited on a Pt electrode at $0.70 \mathrm{~V}$ vs. SCE to a charge of $10.48 \mathrm{C} \mathrm{cm}^{-2}$.

The redox properties of the conducting polymer, polypyrrole, PPy, make it ideal for use as a sensor; as the potential is cycled from a low, negative potential to a higher, more positive potential, the properties of the polymer change. In its oxidised state, i.e., at the higher, more positive potentials, the polymer is positively charged. During the CV experiments for the detection of urea, urea is incorporated into the polymer film with potential cycling. When urease enzyme is present within the polymer, the urea interacts with the enzyme, producing ammonia and lowering the $\mathrm{pH}$ at the electrode/polymer interface. Upon further potential cycling, the urea is released from the polymer back into the solution.

When SCD is present within the polymer film, a schematic for which is shown in Fig. 6, the urea is drawn into the cavity of the sulfonated cyclodextrin, whereby an inclusion complex is formed. SCD has a high affinity for urea; thereby increasing the oxidation charge observed for urea in the PPy-SCD polymer film. When both urease and SCD are present, the observed oxidation charge is even higher due to the interaction of urea with both the urease enzyme and the cyclodextrin.

Typical calibration curves recorded for the PPy-Cl, PPy-Urs-Cl, PPy-SCD and PPy-Urs-SCD films with the oxidation charge plotted as a function of the urea concentration are presented in Fig. 7. Good linearity was achieved with each of the polymer films and the sensitivity of the films towards urea was calculated at 0.43, 0.76, 2.29 and $5.79 \mu \mathrm{C} \mu \mathrm{M}^{-1}$ for the PPy-Cl, PPy-Urs-Cl, PPy-SCD and PPyUrs-SCD films, respectively. This is comparable to the sensitivity of other urea sensors [33], as reported in Table 1. As expected, the $\mathrm{PPy}-\mathrm{Cl}$ film has little sensitivity towards urea, with a sensitivity of only $0.43 \mu \mathrm{C} \mu \mathrm{M}^{-1}$. However, the PPy-SCD polymer film has a greater sensitivity towards urea than the PPy-Urs-Cl film, which only has a sensitivity of $0.76 \mu \mathrm{C} \mu \mathrm{M}^{-1}$ compared to $2.29 \mu \mathrm{C} \mu \mathrm{M}^{-1}$ for the SCD-containing film. Clearly, the PPy-Urs-SCD film has superior sensitivity compared to the other films and the dopant anion has an important role to play in the sensitivity of these films for urea detection. It is well known that cyclodextrins can form inclusion complexes with a variety of guest molecules and the formation of an inclusion complex between the SCD and the urea is consistent with the enhanced sensitivity of the SCD-containing films [33].

\subsection{Selectivity studies of the PPy-Urs-SCD polymer films}

Because SCD is a large anionic species [34], this anionic character may be sufficient to repel anionic interfering compounds such as ascorbic acid and uric acid [35]. To investigate this, the 
(a)

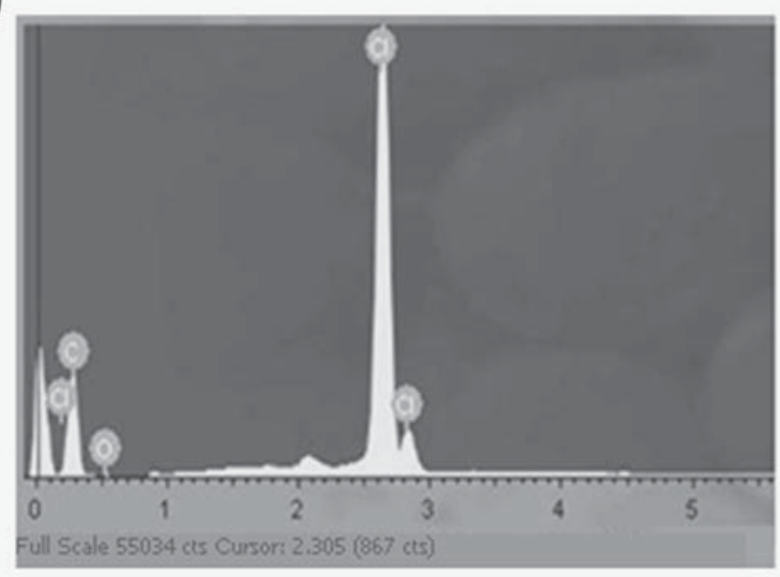

(c)

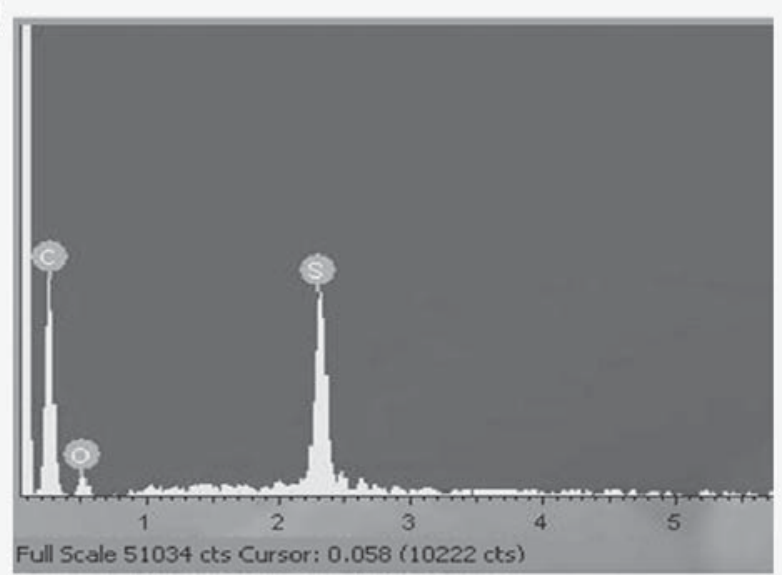

(b)

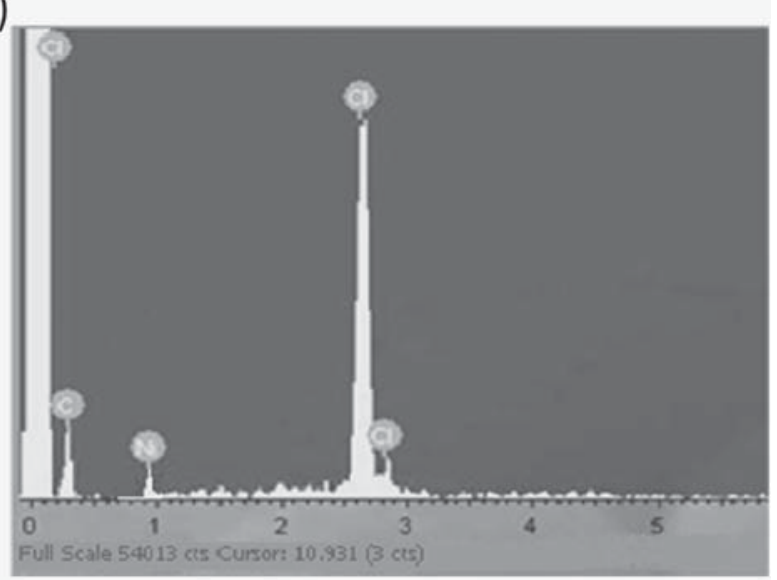

(d)

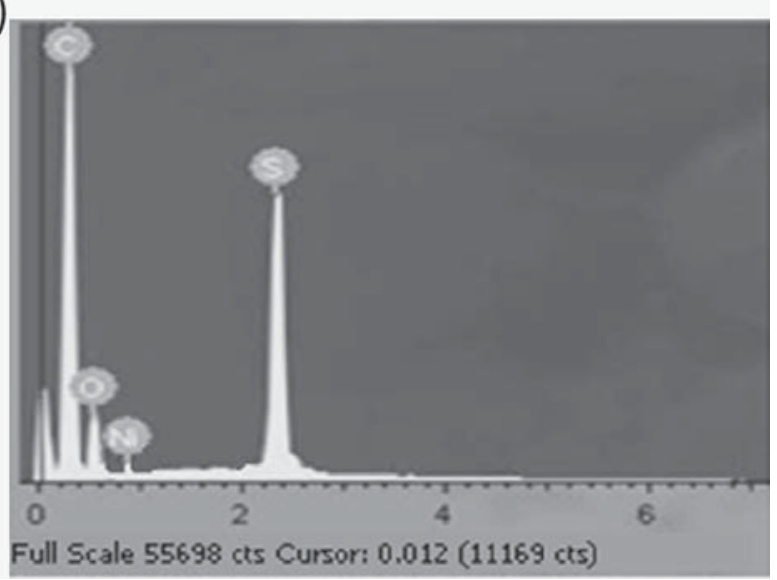

Fig. 4. EDX analysis of (a) PPy-Cl, (b) PPy-Urs-Cl, (c) PPy-SCD and (d) PPy-Urs-SCD electrodeposited onto a platinum electrode at an applied potential of 0.70 V vs. SCE until a charge of $10.48 \mathrm{C} \mathrm{cm}^{-2}$ was reached.

Table 1

Comparison of characteristics of urea biosensors (taken from [33]).

\begin{tabular}{|c|c|c|c|c|c|}
\hline Matrix used & Transducer & Stability & Linear range & Detection limit & Response time \\
\hline Polypyrrole-urease-SCD* & Coloumbometric & - & & & \\
\hline Polypyrrole & Potentiometric & - & $31.8 \mathrm{mV} / \mathrm{dl}$ & - & - \\
\hline Polypyrrole & Amperometric & 2 weeks & - & 60 ug/l & - \\
\hline Poly pyrrole & Amperometric & - & - & $3 \mathrm{ppm}$ & - \\
\hline $\begin{array}{l}\operatorname{Poly}(N-3- \\
\text { aminopropylpyrrole-co- } \\
\text { pyrrole) } \\
\text { film }\end{array}$ & Potentiometric & 2 months & $27.5 \mathrm{mV} / \mathrm{dl}$ & & $25-50 s$ \\
\hline $\begin{array}{l}\text { Urease onto } \mathrm{Si} / \mathrm{SiO} 2 \\
\text { Structure }\end{array}$ & CV measurements & Few days & $22 \mathrm{mV} / \mathrm{P}$ urea & $1 \mathrm{mM}$ & - \\
\hline $\begin{array}{l}\text { Polypyrrole and polyion } \\
\text { complex }\end{array}$ & Potentiometric & $\begin{array}{l}\text { Operational } \\
\text { stability of }>10 \\
\text { usages } / 0.1 \mathrm{M} \\
\text { Tris- } \mathrm{HCl}\end{array}$ & $\begin{array}{l}3 \times 10^{-3} \text { to } \\
3 \times 10^{-1} \mathrm{M}\end{array}$ & $3 \times 10^{-5} \mathrm{M}$ & $20 \mathrm{~s}$ \\
\hline $\begin{array}{l}\text { Polyurethane acylate } \\
\text { polymeric membrane }\end{array}$ & Potentiometric (ISFET) & $>30$ days $/ 4 \circ \mathrm{C}$ & $0.04-36 \mathrm{mM}$ & $0.04 \mathrm{mM}$ & $30 \mathrm{~s}$ to $5 \mathrm{~min}$ \\
\hline $\begin{array}{l}\operatorname{Poly}(N \text {-vinyl } \\
\text { carbazole/stearic acid }) \\
\text { Langmuir-Blodgett film }\end{array}$ & Potentiometric & 5 weeks at $4 \circ \mathrm{C}$ & $0.5-68 \mathrm{mM}$ & $0.5 \mathrm{mM}$ & $2 \mathrm{~min}$ \\
\hline $\begin{array}{l}\text { Triacetyl cellulose } \\
\text { membrane }\end{array}$ & Optical & $\begin{array}{l}60 \text { days stored } \\
\text { wet } / 4 \circ C \text { (with } 20 \% \\
\text { loss) }\end{array}$ & $1-500 \mathrm{mM}$ & $1 \mathrm{mM}$ & $1-5 \mathrm{~min}$ \\
\hline Polyurethane film & Optical & - & $0.7-8 \mathrm{mM}$ & $20 \mu \mathrm{M}$ & $20 \mathrm{~s}$ \\
\hline Nylon net & Amperometric & 4 days & $10^{-5}$ to $3 \times 10^{-4} \mathrm{M}$ & $10^{-5} \mathrm{M}$ & - \\
\hline
\end{tabular}

*The PPy-Urs-SCD film as described by authors. 


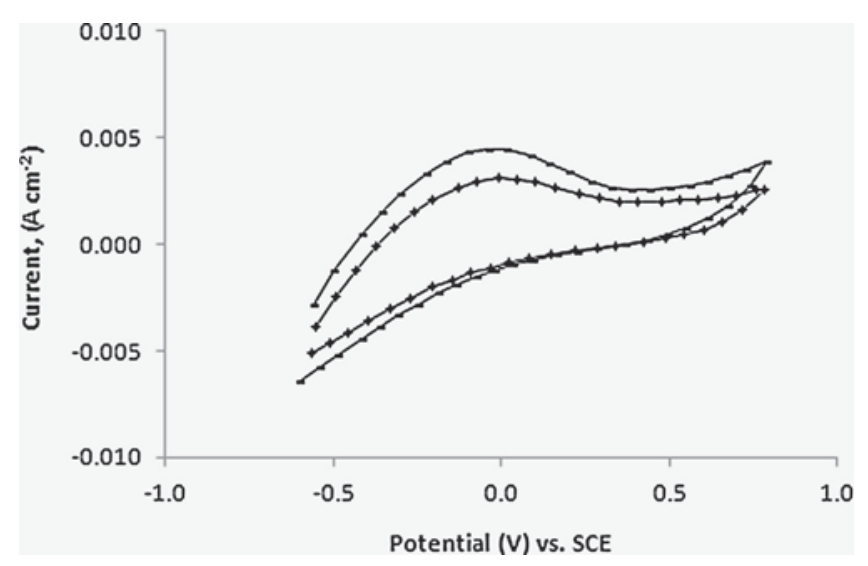

Fig. 5. Cyclic voltammograms recorded for the PPy-Urs-Cl polymer film in the presence and $\downarrow \downarrow$ absence of urea.

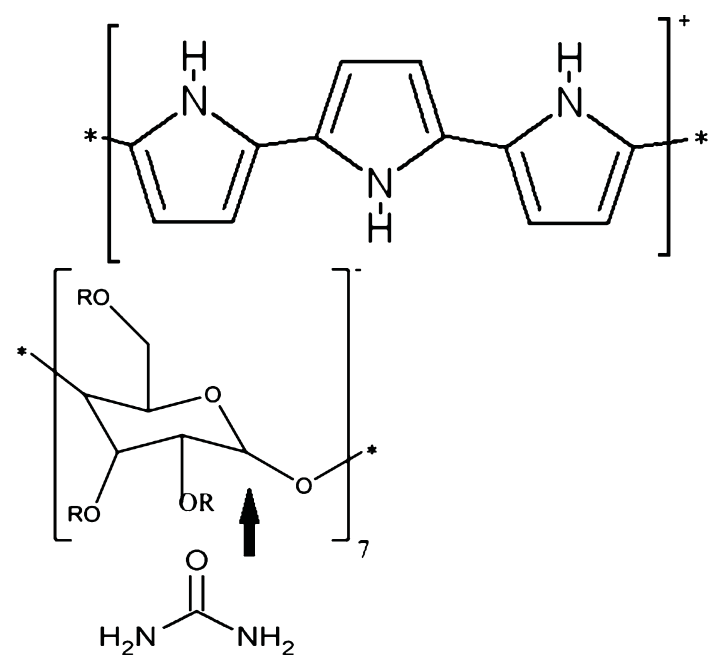

Fig. 6. A schematic of the response mechanism for the detection of urea, when the SCD is used as the dopant anion for polypyrrole.

PPy-Urs-SCD polymer was deposited as detailed in Section 3.1 and cycled in a urea solution in the presence and absence of the interfering compounds (ICs). In each case, the urea concentration was varied from $1.0 \times 10^{-10}$ to $1.0 \times 10^{-2} \mathrm{M}$, while a fixed concentration of $1.0 \times 10^{-4} \mathrm{M}$ of the interfering compound was added to give IC/urea concentration ratios ranging from $1.0 \times 10^{6}$ to $1.0 \times 10^{-2}$. The oxidation charge was recorded in the urea solutions and then compared with the charge recorded in the mixed urea and IC solution.

Ascorbic acid (AA) has a $\mathrm{pKa}$ value of 4.10 and at the $\mathrm{pH}$ of the phosphate buffer solution ( $\mathrm{pH}=7.0)$, dissociation of AA occurs to favour the ascorbate anion. It is clear from Fig. 8 that there is no interference observed when AA is added to the urea solution at the PPy-Urs-SCD polymer films. The oxidation charges obtained from cycling the polymer in a urea solution in the absence of AA are similar to those obtained on cycling the polymer film in a urea solution in the presence of AA. Regardless of the ratio of AA to urea, which is in the vicinity of $1.0 \times 10^{6}$ at the low concentrations of urea, there is no evidence of any interference from the added AA.

These data can be explained in terms of the negative charges of the sulfonated groups on the $\beta$-cyclodextrin within the PPy-UrsSCD film, which provide a highly negative local charge. In addition, some free- $\mathrm{SO}_{3}-$ groups are likely to exist at the PPy-Urs-SCD surface [36]. It is likely that the negatively charged sulfonated groups on the $\beta$-cyclodextrin are successful in repelling the anionic ascorbate from the surface of the electrode and hence, the urea can be

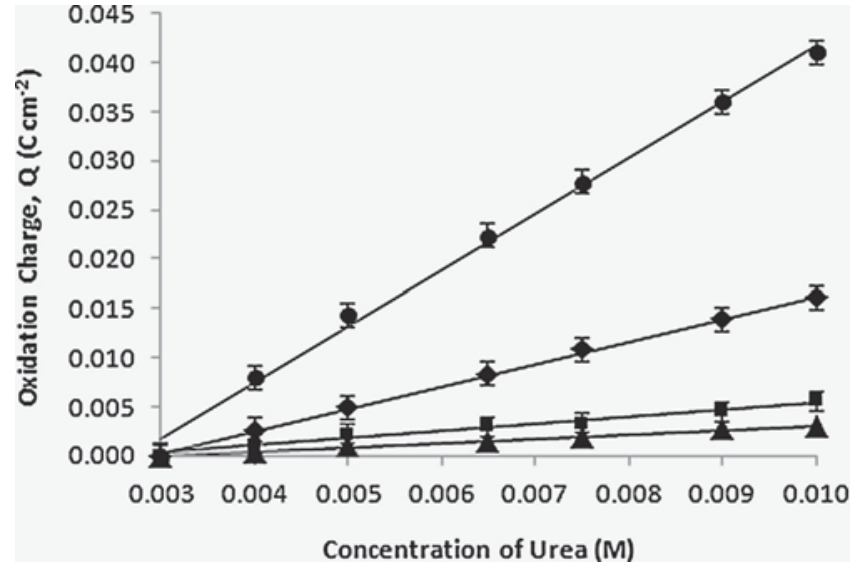

Fig. 7. Calibration curve $(n=6)$ with the oxidation charge plotted as a function of the urea concentration for $\bullet \bullet$ PPy-Urs-SCD, $\diamond \diamond$ PPy-SCD, $\square$ mPy-Urs-Cl and $\Delta \mathbf{\Delta} \mathrm{PPy}-\mathrm{Cl}$ films at the higher urea concentration levels.

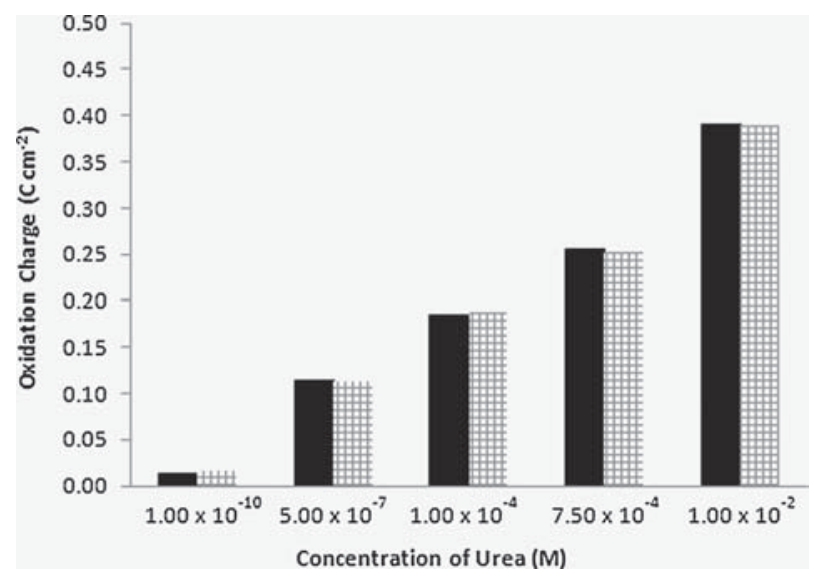

Fig. 8. Charge plotted at different urea concentrations in the - absence and presence of $1.0 \times 10^{-4} \mathrm{M}$ AA at the PPy-Urs-SCD polymer films.

detected without any interference from AA, as clearly shown in Fig. 8.

As uric acid (UA) has a $\mathrm{p} K_{\mathrm{a}}$ value of 5.4 [37], it is predominantly anionic at the biological $\mathrm{pH}$ of the phosphate buffer solution; therefore, as with the AA, it is expected that the anionic nature of the SCD [38], incorporated within the PPy-Urs-SCD polymer film, would be sufficient to repel the uric acid/ureate anion from the electrode surface. However, as shown in Fig. 9, where the oxidation charge is plotted as a function of urea concentration in the absence and presence of a fixed concentration of UA, at $1.0 \times 10^{-4} \mathrm{M}$, it is clear that higher charges are recorded in the presence of UA, regardless of the urea concentration, or indeed the ratio of the UA to urea. When the concentration of urea is $1.0 \times 10^{-2} \mathrm{M}$ to give a concentration ratio of urea:UA of 1.00:0.01, the charge is increased from $0.40 \mathrm{C} \mathrm{cm}^{-2}$ to $0.48 \mathrm{C} \mathrm{cm}^{-2}$, giving a $20 \%$ increase in the measured charge. This increase is maintained when the ratio of urea:UA is varied. For example, a $22 \%$ increase in the charge is observed when the concentration of urea is $5.0 \times 10^{-7} \mathrm{M}$ to give a urea:UA ratio of $1: 10^{3}$. This suggests that the observed increase in the charge is not connected with the concentration of urea, but is related to the uric acid only. This increase in the charge in the presence of UA is a surprising result since most interfering compounds tend to foul, adhere to and block the surface of the electrode [39]. As a result, the signal is lost or lowered significantly. However, this is not the case as shown in Fig. 9. 


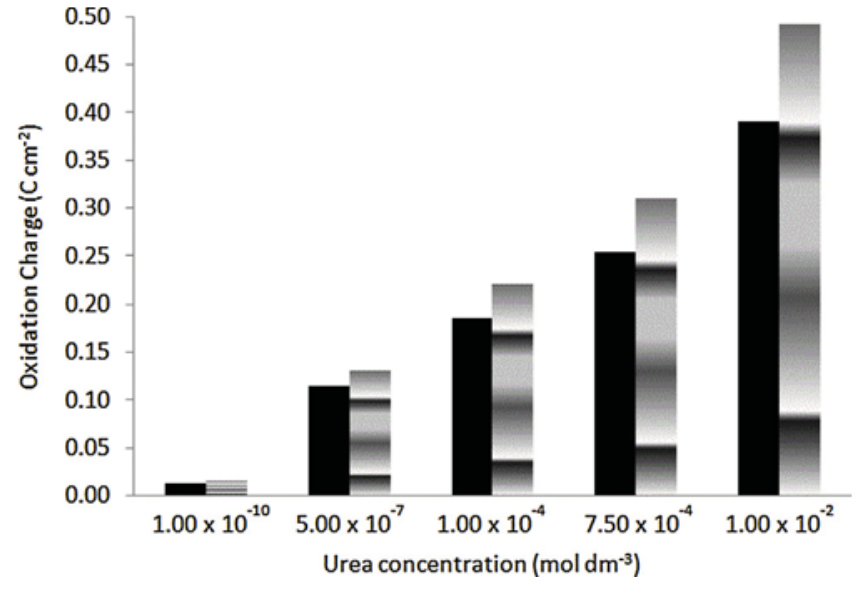

Fig. 9. Charge plotted at different urea concentrations in the - absence and presence of $1.0 \times 10^{-4} \mathrm{M} U A$ at the PPy-Urs-SCD polymer films.

One possible explanation to account for this observation is the diffusion of UA through the polymer film to the polymer-electrode interface, where oxidation of UA occurs. The PPy-Urs-SCD film is quite porous, as is evident from the SEM micrographs shown in Fig. 3 , due to the large sulfonated- $\beta$-cyclodextrin competing for space with the equally large urease enzyme within the polymer film. This may facilitate the diffusion of UA. This possibility was explored by using polymer films deposited to different thickness.

For this study, $\mathrm{PPy}-\mathrm{Cl}$ and $\mathrm{PPy}-\mathrm{Urs}-\mathrm{Cl}$ polymer films were chosen. The polymer films were deposited to different charges, ranging from 0.01 to $0.74 \mathrm{C} \mathrm{cm}^{-2}$. Once deposited, the films were cycled in the buffered $0.01 \mathrm{~mol} \mathrm{dm}^{-3}$ urea solution, in the absence and presence of $1.0 \times 10^{-4} \mathrm{~mol} \mathrm{dm}{ }^{-3} \mathrm{UA}$. It was found that the thickness of the polymer film had a significant influence on the measured oxidation charge. When relatively thin $\mathrm{PPy}-\mathrm{Cl}$ films were used, the charges recorded in the presence of UA were significantly higher, as shown in Fig. 10 (a). However, when the thickness of the PPy-Cl films was increased, the charges recorded in the urea solution were similar in the presence and absence of UA, as highlighted in Fig. 10 (b).

Interestingly, the PPy-Urs- $\mathrm{Cl}$ film, although grown to the same charge as the PPy-Cl film, does not allow the UA to reach the electrode surface as readily. This is clearly evident in Fig. 10 (a) where the presence of UA leads to a significant increase in the charge recorded at the $\mathrm{PPy}-\mathrm{Cl}$, but not at the PPy-Urs- $\mathrm{Cl}$ films. This may be related to the fibrous morphology observed for the PPy-Urs-Cl film, compared to the cauliflower-like morphology of the $\mathrm{PPy}-\mathrm{Cl}$ film. The pores in the PPy-Urs-Cl polymer film are blocked by the large enzyme and this may inhibit the diffusion of UA throughout the polymer film. However, the morphology of the PPy-Urs-SCD films is very different and more porous, enabling the diffusion of UA to the substrate interface.

This clearly shows that while the anionic charge provided by the SCD is important in eliminating interference from AA, the porosity of the polymer film is also significant. Therefore, the deposition of a thin layer of the more compact PPy-Urs-Cl film followed by a thicker PPy-Urs-SCD film could be used to reduce the porosity and the rate of diffusion of the interfering compounds through the polymer film, while still maintaining a good sensitivity towards urea.

The same analysis was carried out in the presence of thiourea (TU), hydroxyurea (HU) and creatinine (CR) and these data are shown in Fig. 11, while the influence of ammonium chloride (AC) is shown in Fig. 12. These interfering compounds are neutral at the $\mathrm{pH}$ of these experiments ( $\mathrm{pH}$ of 7.0).

Fig. 11 shows that there is no evidence of any interference for all the interfering compounds, at the lowest urea concentration of $1.0 \times 10^{-10} \mathrm{M}$, but at the higher urea concentrations the presence of the interfering compound yields higher charges. This increase is (a)

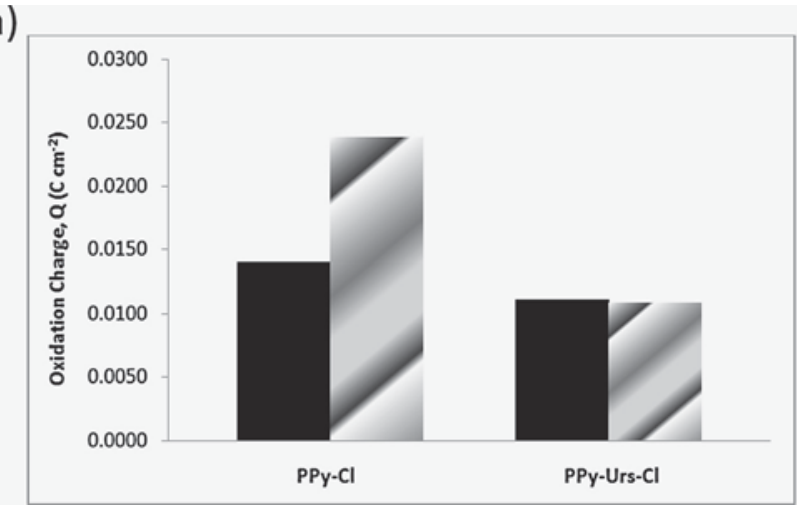

(b)

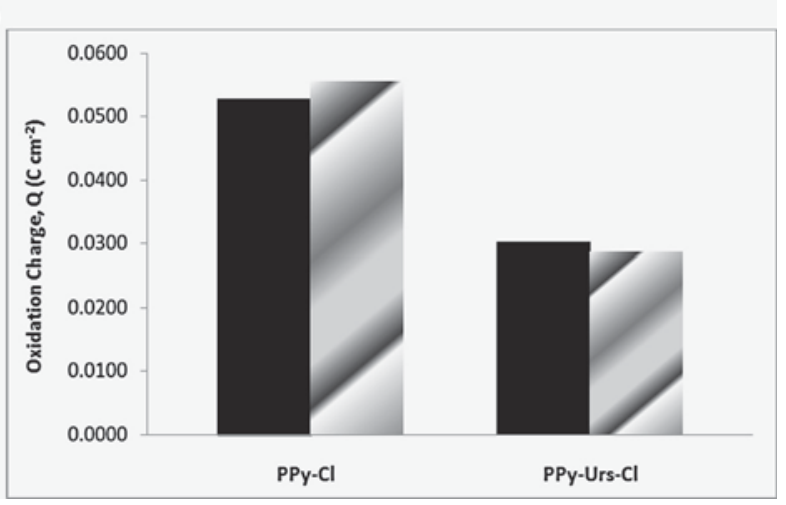

Fig. 10. Oxidation charge recorded $\left(5^{\text {th }}\right.$ cycle) for the PPy-Cl and PPy-Urs-Cl polymer films grown to a charge of (a) $0.017 \mathrm{C} \mathrm{cm}^{-2}$ and $(\mathrm{b}) 0.74 \mathrm{Ccm}{ }^{-2} \mathrm{cycled}$ in a $0.01 \mathrm{~mol}$ $\mathrm{dm}^{-3}$ solution of urea in the - presence and - absence of $1.0 \times 10^{-4} \mathrm{~mol} \mathrm{dm}{ }^{-3}$ uric acid.
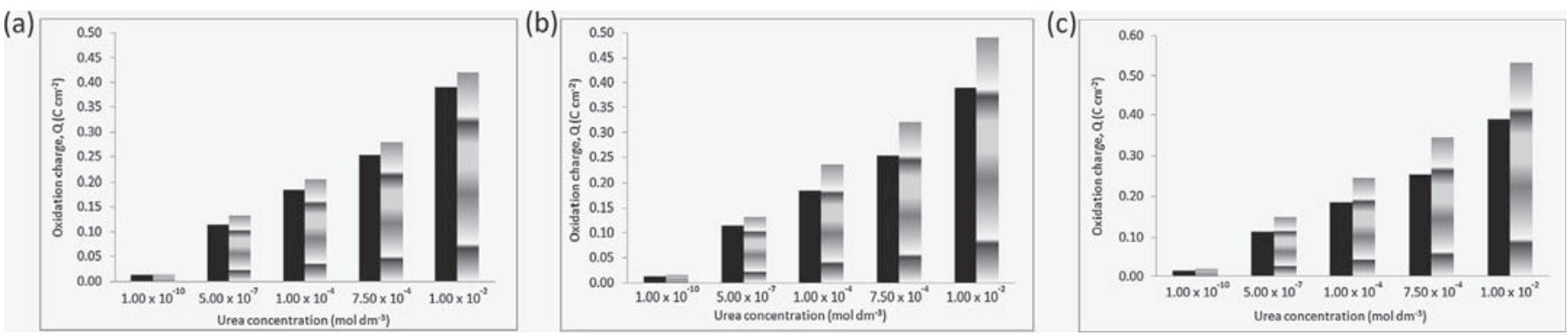

Fig. 11. Charge plotted at different urea concentrations in the - absence and - presence of (a) $1.0 \times 10^{-4} \mathrm{M} \mathrm{TU}$, (b) $1.0 \times 10^{-4} \mathrm{M} \mathrm{HU}$ and (c) $1.0 \times 10^{-4} \mathrm{M} \mathrm{CR}$ at the PPy-Urs-SCD polymer films. 


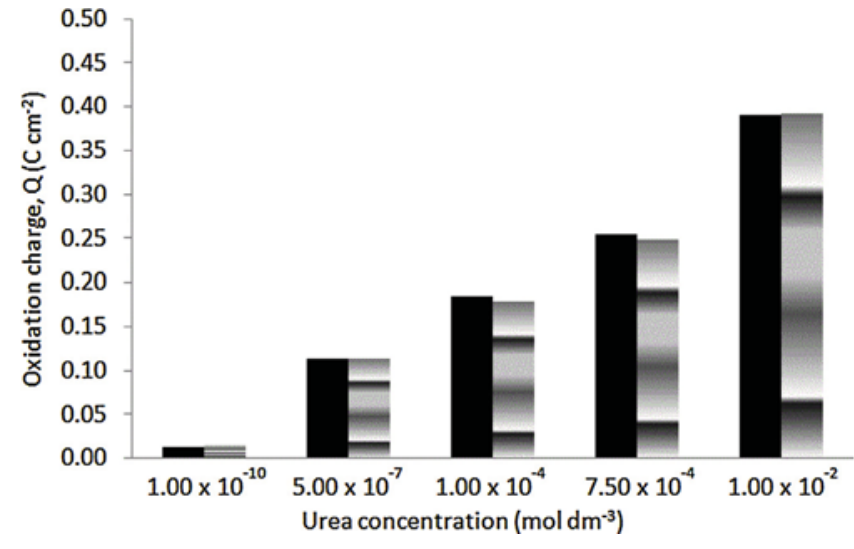

Fig. 12. Charge plotted at different urea concentrations in the - absence and presence of $1.0 \times 10^{-4} \mathrm{M} \mathrm{NH}_{4} \mathrm{Cl}$ at the PPy-Urs-SCD polymer films.

less significant than that observed with UA, Fig. 9. Again, this could be due to the diffusion of the interfering compound throughout the porous polymer film and its oxidation at the substrate electrode.

Ammonium chloride, $\mathrm{NH}_{4} \mathrm{Cl}$, is non-electroactive, however, $\mathrm{NH}_{4}{ }^{+}$is produced during the hydrolysis of urea and consequently its influence on the electrochemical detection of urea is important in the development of a urea sensor. The charge plotted at different urea concentrations in the absence and presence of $1.0 \times 10^{-4} \mathrm{M} \mathrm{NH}_{4} \mathrm{Cl}$ is presented in Fig. 12. There is no evidence of any interference from the $\mathrm{NH}_{4} \mathrm{Cl}$. Furthermore, there was no evidence of any surface fouling in the presence of $\mathrm{NH}_{4} \mathrm{Cl}$. These data clearly show that urea can be detected with the PPy-Urs-SCD film in the presence of $\mathrm{NH}_{4}{ }^{+}$without any interference or surface fouling. This proves that the PPy-Urs-SCD polymer film not only enhances detection of urea but indeed, it also inhibits or eliminates fouling of the electrode by common biological salts, such as $\mathrm{NH}_{4} \mathrm{Cl}$.

\section{Conclusions}

Two urease-containing polypyrrole films, PPy-Urs-Cl and PPyUrs-SCD, were successfully developed and characterised. It was concluded that the urease enzyme was successfully incorporated via physical entrapment during electrodeposition of the polymer films due to the presence of nickel in the EDX spectra. A porous film was obtained in the presence of both the SCD and urease enzyme, while a more compact structure was observed with the PPy-Urs-Cl film. The sensing ability of each of the films and their enzyme-free counterparts (i.e., $\mathrm{PPy}-\mathrm{Cl}$ and $\mathrm{PPy}-\mathrm{SCD}$ ) towards urea was investigated. The dopant anion plays an important role in the sensitivity of the polymer films towards urea, as the PPy-Urs-SCD film has a superior sensitivity of $5.79 \mu \mathrm{C} \mu \mathrm{M}^{-1}$ compared to $0.76 \mu \mathrm{C} \mu \mathrm{M}^{-1}$ for the PPy-Urs-Cl polymer film. The selectivity of the PPy-Urs-SCD film was also investigated using a wide range of interfering compounds. The interference was eliminated completely from ascorbic acid (AA), however higher charges were observed in the presence of uric acid (UA). This was explained in terms of the film porosity and on reducing the porosity the interference was minimised. It was found that the film porosity could be easily reduced by initially depositing a thin layer of the more compact Py-Urs-Cl followed by the PPy-Urs-SCD film, to give an ideal urea sensor with excellent sensitivity, selectivity and limit of detection.

\section{Acknowledgements}

The authors would like to thank the Irish Research Council for the financial support received for this project.

\section{References}

[1] G. Dhawan, G. Sumana, B.D. Malhotra, Biochem. Eng. J. 44 (2009) 42.

[2] M.-J. Syu, Y.-S. Chang, Biosens. Bioelectron. 24 (2009) 2671.

[3] Y.-C. Luo, J.-S. Do, Biosens. Bioelectron. 20 (2004) 15.

[4] S. Cosnier, Biosens. Bioelectron. 14 (1999) 443.

[5] G.C. Guilbault, J.G. Montalve Jr., J. Am. Chem. Soc. 92 (1970) 2533.

[6] P.N. Bartlett, J.M. Cooper, J. Electroanal. Chem. 363 (1993) 1.

[7] S. Komaba, M. Seyama, T. Momma, T. Osaka, Electrochim. Acta 42 (3) (1997) 383.

[8] T. Osaka, S. Komaba, M. Seyama, K. Tanabe, Sens. Actuators B: Chem. 35-36 (1996) 463.

[9] B. Lakard, D. Magnin, O. Deschaume, G. Vanlancker, K. Glinel, S. DemoustierChampagne, B. Nysten, A.M. Jonas, P. Bertrand, S. Yunus, Biosens. Bioelectron. 26 (10) (2011) 4139.

[10] N. Gupta, S. Sharma, I.A. Mir, D. Kumar, J. Sci. \& Ind. Res. 65 (2006) 549.

[11] S.B. Adeloju, S.J. Shaw, G.G. Wallace, Anal. Chim. Acta 323 (1996) 107.

[12] S.B. Adeloju, S.J. Shaw, G.G. Wallace, Anal. Chim. Acta 341 (1997) 155

[13] I. Walcerz, S. Glab, R. Koncki, Anal. Chim. Acta 369 (1998) 129.

[14] B. Kovacs, N. Gesa, R. Dombi, T. Klara, Biosens. Bioelectron. 18 (1999) 111.

[15] M.L. Hamlaoui, K. Reyier, M. Marrakchi, N. Jaffrezic-Renault, C. Martelet, R. Kherrat, A. Walcarius, Anal. Chim. Acta 466 (2002) 39.

[16] A.P.Soldatkin, V. Volotovsly, A.V.El'skaya, N. Jaffrezic-Renault, C. Martelet, Anal. Chim. Acta 403 (2000) 25.

[17] A.P. Soldatkin, J. Montoriol, W. Sant, C. Martelet, N. Jaffrezic-Renault, Biosens. Bioelectron. 19 (2003) 131.

[18] Rajesh, V. Bisht, W. Takashima, K. Kaneto, React. Funct. Pol. 62 (2005) 51

[19] V. Rajesh, W. Bisht, K. Takashima, Kaneto, Surf. Coat. Technol. 198 (2005) 231.

[20] V. Rajesh, W. Bisht, K. Takashima, Kaneto, Biomaterials 26 (2005) 3683.

[21] M. Singh, N. Verma, A.K. Garg, N. Redhu, Sens. Actuators B: Chem. 134 (2008) 345.

[22] G.B. Kistiakowsky, P.C. Mangelsdorf Jr., A.J. Rosenberg, W.H. R. Shaw, J. Am. Chem. Soc. 74 (20) (1952) 5015.

[23] A.F. Diaz, J.I. Castillo, J.A. Logan, W.Y. Lee, J. Electroanal. Chem. 129 (1981) 115

[24] J. Tietje-Girault, C. Ponce De Leon, F.C. Walsh, Surf. Coat. Technol. 201 (2007) 6025.

[25] C.E. Schmidt, J.M. Fonner, L. Forciniti, H. Nguyen, J.D. Byrne, Y.F. Kou, J. SyedaNawaz, Biomed. Mater. 3 (2008) 034124.

[26] A. Ramanavicius, A. Ramanaviciene, A. Malinauskas, Electrochim. Acta 51 (2006) 6025.

[27] T.de.J. Licona-Sanchez, G.A. Alvarez-Romero, L.H. Mendoza-Huizar, C.A. GalanVidel, J. Phys. Chem. 114 (2010) 9737.

[28] T.de.J. Licona-Sanchez, G.A. Alvarez-Romero, M. Palomar-Pardave, C.A. GalanVidel, M.E. Paez-Hernandez, M.T. Ramirez Silva, M. Romero-Romo, Int. J. Electrochem. Sci. 6 (2011) 1537.

[29] M.-C. Shin, H.-S. Kim, Biosens. Bioelectron. 11 (1996) 161.

[30] G.G. Wallace, G.M. Spinks, L.A.P. Kane-Maguire, P.R. Teasdale, Conductive Electroactive Polymers: Intelligent Materials Systems, 237, CRC Press, 2003.

[31] G. Maia, R.M. Torresi, E.A. Ticianelli, F.C. Nart, J. Phys. Chem. 100 (1996) 15910

[32] A.L. Brisena, A. Baca, Q.Z. Zhou, R. Lai, F.M. Zhou, Anal. Chim. Acta 441 (2001) 123.

[33] A. Hamilton, C.B. Breslin, Electrochim. Acta 125 (2014) 250.

[34] A. Amini, T. Rundlof, M.B.G. Rydberg, T. Arvidsson, J. Sep. Sci. 27 (2004) 1102.

[35] H. Zhao, Y. Zhang, Z. Yuan, Anal. Chim. Acta 441 (2001) 117.

[36] S. Suematsu, Y. Oura, H. Tsujimoto, H. Kanno, K. Naoi, Electrochim. Acta 45 (2000) 3813.

[37] J.-M. Zen, J.-J. Jou, G. Ilangovan, Analyst 123 (1998) 1345.

[38] F.T.A. Chen, G. Shen, R.A. Evangelista, Journal of Chromatography A 924 (2001) 523.

[39] R. Gifford, J.J. Kehoe, S.L. Barnes, B.A. Kornilayev, M.A. Alterman, G.S. Wilson, Biomaterials 27 (2006) 2587. 